\title{
Columnar apple primary roots share some features of the columnar-specific gene expression profile of aerial plant parts as evidenced by RNA-Seq analysis
}

Romina Petersen*, Haris Djozgic, Benjamin Rieger, Steffen Rapp and Erwin Robert Schmidt

\begin{abstract}
Background: Primary roots (radicles) represent the first visible developmental stages of the plant and are crucial for nutrient supply and the integration of environmental signals. Few studies have analyzed primary roots at a molecular level, and were mostly limited to Arabidopsis. Here we study the primary root transcriptomes of standard type, heterozygous columnar and homozygous columnar apple (Malus $x$ domestica) by RNA-Seq and quantitative real-time PCR. The columnar growth habit is characterized by a stunted main axis and the development of short fruit spurs instead of long lateral branches. This compact growth possesses economic potential because it allows high density planting and mechanical harvesting of the trees. Its molecular basis has been identified as a nested Gypsy-44 retrotransposon insertion; however the link between the insertion and the phenotype as well as the timing of the phenotype emergence are as yet unclear. We extend the transcriptomic studies of columnar tissues to the radicles, which are the earliest developmental stage and investigate whether homozygous columnar seedlings are viable.
\end{abstract}

Results: Radicles mainly express genes associated with primary metabolism, growth and development. About 200 genes show differential regulation in a comparison of heterozygous columnar radicles with non-columnar radicles, whereas the comparison of homozygous columnar radicles with non-columnar radicles yields about 300 differentially regulated genes. Genes involved in cellulose and phenylpropanoid biosynthesis, cell wall modification, transcription and translation, ethylene and jasmonate biosynthesis are upregulated in columnar radicles. Genes in the vicinity of the columnar-specific Gypsy-44 insertion experience an especially strong differential regulation: the direct downstream neighbor, dmr6-like, is downregulated in heterozygous columnar radicles, but strongly upregulated in columnar shoot apical meristems.

Conclusions: The transcriptomic profile of primary roots reflects their pivotal role in growth and development. Homozygous columnar embryos are viable and form normal radicles under natural conditions, and selection towards heterozygous plants most likely occurs due to breeders' preferences. Cell wall and phytohormone biosynthesis and metabolism experience differential regulation in columnar radicles. Presumably the first step of the differential regulation most likely happens within the region of the retrotransposon insertion and its tissue-specificity suggests involvement of one (or several) tissue-specific regulator(s).

Keywords: Primary root, Homozygous, Columnar, Apple, Gypsy-44, RNA-Seq, DESeq, MapMan, qRT-PCR

\footnotetext{
*Correspondence: peterser@uni-mainz.de

Department of Molecular Genetics, Johannes Gutenberg-University, Mainz D-55128, Germany
} 


\section{Background}

Columnar apple trees show a characteristic pillar-like growth habit with a thick, stunted main axis and short lateral fruit spurs [1,2]. This growth habit could be of potential benefit to apple growers because columnar trees can be planted closer together and require less pruning than standard tree types [2,3]. However, none of the columnar cultivars available to date can compete with commercially successful cultivars in terms of fruit quality and disease resistance [2-7]. Columnar growth arose as a spontaneous somaclonal mutation of a McIntosh tree in Canada in 1961 [8,9]. With one exception [10], all columnar cultivars that have been described so far are heterozygous (hemizygous) for the columnar mutation ( $\mathrm{Co} /-)$ [11]. Whether the lack of homozygous individuals $(\mathrm{Co} / \mathrm{Co})$ is due to a decreased viability of homozygous columnar seeds/seedlings or just the decision of apple growers to preferentially choose non-columnar breeding partners is unclear.

The molecular cause of the columnar phenotype has recently been identified as the insertion of a Gypsy-44 long terminal repeat (LTR) retrotransposon into the LTR of another retrotransposon on chromosome 10 [10]. Wolters et al. [12] detected a smaller columnar-specific insertion at the same position, which is the solo-LTR of Gypsy-44 and thus most likely represents an artefact (unpublished data). The Gypsy-44 insertion is probably responsible for the upregulation of a nearby gene encoding a 2OG-Fe(II) oxygenase (also called downy mildew resistance 6-like (dmr6-like)) of unknown function in apical meristems and axillary buds of columnar trees, whereas leaves do not show any expression of dmr6-like [10,12]. Overexpression of dmr6-like in Arabidopsis thaliana led to a columnar-like phenotype [12]. In addition to the upregulation of dmr6-like, a significant increase of the expression level of other genes within the retrotransposon vicinity has been shown $[10,13]$. The consequence is a change in the overall gene expression pattern of the columnar plants. The shoot apical meristems and leaves of columnar apple trees show a differential regulation of defense-associated genes, genes involved in secondary metabolism such as terpene and phenylpropanoid synthesis, as well as genes related to auxin and jasmonate synthesis and signaling $[10,13,14]$. Since a reliable detection of the columnar growth habit is only possible after about two to three years, it is as yet unclear at which developmental time point the gene expression patterns leading to the formation of the columnar habit are established. Up to now, it is also not known whether and how the gene expression pattern of roots is affected by the Co mutation. Even the phenotype of own roots of columnar apple trees has never been analyzed, which is probably due to the fact that the vast majority of columnar trees are grown as scions on non-columnar rootstocks.
Germination and radicle emergence are the first developmental steps towards the formation of a new plant. The radicle is important for anchorage, nutrient and water supply of the plantlet as well as for the perception and integration of a multitude of environmental signals such as gravity or pest attacks. Its tip has even been described as the "brain" of the plant by Charles Darwin [15] (cited in [16]). Despite their crucial regulatory and pioneering role in development, little research has been conducted on primary roots at the molecular level (e.g. deciphering their transcriptome profiles) and those were mainly limited to the model plants Arabidopsis thaliana and Zea mays (for example [17-21]). Only one publication has dealt explicitly with the transcriptome of adult roots of poplar [22]. While apple seeds have been the subject of several studies mostly owing to their deep and well-pronounced dormancy [23-28], research interest seems to fade significantly when they finish germination. Apple seed dormancy can be overcome by cold treatment (stratification) for 60 - 90 days depending on the cultivar and environmental conditions $[23,28]$. After this time, the radicle protrudes the testa as the primary root. Primary roots of the dicotyledonous model plant Arabidopsis consist of four longitudinal sections: the root cap (columella) at the tip, followed by the zone of division, the elongation zone and the differentiation zone [29]. A cross section of the root reveals a radial organization of different cell layers: epidermis, cortex, endodermis and the vascular cylinder encompassing the pericycle, protoxylem, protophloem and procambium [30,31]. This radial symmetry is established at the root apical meristem, a small set of cells near the root tip surrounding the mitotically less active quiescent center [32].

In this study we analyzed and compared the transcriptomes of heterozygous columnar, homozygous columnar and non-columnar primary apple roots. Our aims were 1) to gather general information about the gene expression profile of this poorly studied plant tissue, 2) to analyze whether homozygous columnar seedlings exist and are viable, 3) to determine whether the columnar-specific gene expression profile observed in aerial plant parts can already be observed at the earliest stages of development in the root and 4) to further investigate how the Gypsy-44 insertion might be linked to the formation of the growth phenotype. For this purpose, apple seeds were subjected to stratification and radicles were harvested when they had reached a length of about $3 \mathrm{~cm}$. Half of the radicle was used for DNA isolation and subsequent genotyping, while the remaining half containing the root tip was used for RNA isolation followed by Illumina sequencing. The transcriptomic reads were assembled and contigs were subjected to Basic Local Alignment Search Tool (BLAST) searches [33] as well as Blast2GO analyses [34,35] to gain a comprehensive view of the genes expressed in primary apple roots in general. Furthermore, the reads were 
mapped to the apple draft genome [36] and individual gene expression levels (normalized read counts) were compared between columnar and non-columnar radicles, with a special focus on the genes in the vicinity of Gypsy-44, the Co mutation. Gene expression patterns in the Co target region were compared across primary roots, leaves and shoot apical meristems by additional quantitative real-time PCRs (qRT-PCRs). Similarities and differences in the gene expression patterns of the different tissues were found. Our data make a substantial contribution to the understanding of the development of the columnar growth habit and primary root function in general.

\section{Results}

\section{Homozygous columnar apple seedlings are viable}

To investigate whether homozygous columnar apple seedlings show reduced viability or phenotypic effects compared to standard-type seedlings in early developmental stages, seeds obtained from apples of the heterozygous columnar cultivar 'Procats 28' (P28) that had been subjected to open pollination were germinated. As the trees were grown surrounded by other columnar apple varieties, the chance of pollination by a columnar father was high. After about 12 weeks of incubation at $4^{\circ} \mathrm{C}$, the germination rate of the seeds was approximately $80 \%$. No obvious phenotypic differences could be observed between individual radicles. The radicle genotype with regard to the presence of the columnar-specific Gypsy-44 transposable element (TE), which most likely represents the original Co mutation [10], was determined via PCRs. The diagnostic PCR assays as established by Otto et al. discriminate unambiguously between the non-columnar, the heterozygous columnar and the homozygous columnar genotype [10]. Of 119 seedlings subjected to genotyping, 40 seedlings were detected to be non-columnar, 59 showed a heterozygous columnar genotype, while the remaining 20 seedlings carried the columnar-specific Gypsy-44 insertion homozygously. These results could be confirmed by PCR assays using our indel-based markers I2_3_M1 and H1_M1 that are tightly linked to the Co mutation [37]. In total, a genotype ratio of non-columnar : heterozygous columnar : homozygous columnar seedlings of $2: 3: 1$ (Figure 1) was detected. This suggests that homozygous columnar apple embryos are viable and most likely germinate at normal ratios.

Primary roots mainly express genes for growth, development and signaling

We sequenced RNA extracted from one primary root of each genotype and obtained about 118 million, 104 million and 126 million reads for the non-columnar, the heterozygous columnar and the homozygous columnar sample, respectively [EMBL: PRJEB6212] (Table 1). In order to investigate biological replicates, in a second

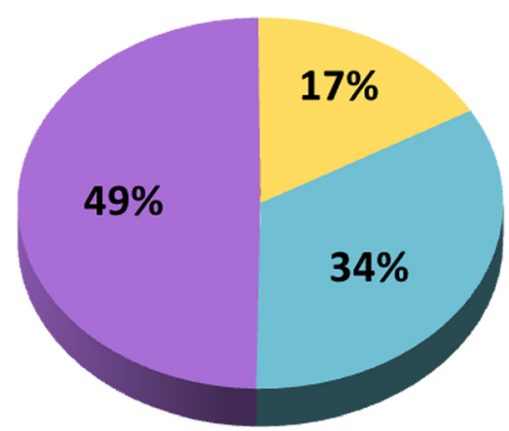

non-columnar $\quad$ heterozygous homozygous columnar

Figure 1 Genotypes of primary roots. The genotype of 119 apple primary roots was determined by marker PCRs with regard to the presence of the Gypsy-44 retrotransposon insertion.

approach, three radicles of each genotype were pooled prior to RNA isolation and were subjected to Illumina sequencing, yielding about 40 million, 28 million and 67 million reads for the non-columnar, the heterozygous columnar and the homozygous columnar sample, respectively [EMBL: PRJEB6212]. Illumina reads were assembled in the CLC Assembly Cell using different k-mer sizes, and assemblies yielding the highest N50 value were used for downstream analysis. For the first datasets comprising more than 100 million sequences, the highest N50 values were obtained for $\mathrm{k}=17$, for the smaller replicate datasets for $\mathrm{k}=18$. Table 1 summarizes the assembly results. In the larger datasets, about 44,000 - 49,000 contigs were produced, whereas assemblies of the smaller datasets yielded about $28,000-38,000$ contigs. N50 values were in the range of $1,200-1,500 \mathrm{bp}$. With no mismatches allowed, more than $40 \%$ of the trimmed reads of each dataset could be mapped back to the corresponding contigs.

In order to find out how many and which genes were represented in the datasets, BLAST searches were conducted with all contigs against the annotated apple genes (MDPs), Malus x domestica expressed sequence tags (ESTs), Malus $\mathrm{x}$ domestica unigenes and the SwissProt/UniProtKB database (Table 2 and Table 3). A maximum of $89 \%$ of the sequences matched to a homolog in the MDP list, whereas only up to $60 \%$ of the contigs had a match against the SwissProt/UniProtKB database. Only up to 19 contigs had the same hit in the MDP database (meaning they most likely represent fragments of the same gene), indicating that about $89 \%$ of the contigs represent different genes. By contrast, up to 266 contigs yielded the same SwissProt/UniProtKB hit, thereby reducing the number of individual genes detected to about 11,500 (44\% of the contigs created).

Replicate datasets were subjected to Blast2GO analysis. Of the sequences yielding BLAST hits against SwissProt/ UniProtKB, $51 \%$ - 63\% were successfully annotated. 
Table 1 Results of assemblies

\begin{tabular}{|c|c|c|c|c|c|c|c|c|}
\hline & \# raw seqs & k-mer size & \# contigs & GC content (\%) & Longest contig & Shortest contig & N50 & Reads mapped back (\%) \\
\hline PR (-/-) & 118400555 & 17 & 48023 & 43 & 9994 & 200 & 1484 & 63 \\
\hline PR (Co/-) & 104464241 & 17 & 44197 & 44 & 10381 & 200 & 1455 & 59 \\
\hline PR (Co/Co) & 125731385 & 17 & 48932 & 43 & 16563 & 200 & 1487 & 60 \\
\hline PRs (-/-) & 40261320 & 18 & 32471 & 45 & 11741 & 200 & 1288 & 43 \\
\hline PRs (Co/-) & 27708416 & 18 & 28493 & 45 & 13248 & 200 & 1242 & 40 \\
\hline PRs (Co/Co) & 67322394 & 18 & 37527 & 44 & 8970 & 200 & 1329 & 52 \\
\hline
\end{tabular}

Illumina sequences were assembled and key values for contigs are indicated. The percentage of reads that was successfully mapped back to the contigs as a reference is shown in the last column.

About 86,000 - 100,000 Level 2 gene ontology (GO) terms were assigned (see Additional file 1), half of which were associated with growth and development (categories "metabolic process", "growth", "developmental process" and "cellular component organization or biogenesis") or with the integration and reaction to environmental signals (categories "response to stimulus", "biological regulation" and "signaling"). This is in line with the major roles of primary roots.

\section{Differential gene expression in columnar versus non-columnar radicles is widespread}

For evaluation of differential gene expression we chose a mapping approach rather than an assembly approach. For each sample, reads were mapped against the annotated Golden Delicious genome [36], total read counts for each MDP were extracted, and differential gene expression across the three genotypes was statistically analyzed in DESeq [38]. Highly expressed (base mean $>100$ ), significantly up- or downregulated genes (fold change $>2$ or $<0.5$ and p-value $<0.05)$ were visualized in MapMan [39]. A Venn diagram showed high overlap of active genes (represented as MDPs to which at least one read was mapped) between the three genotypes (see Additional file 2). Furthermore, all libraries showed a high degree of correlation, with Pearson correlation coefficients ranging from $0.80-0.98$, indicating that overall gene expression was similar across genotypes and that replicate datasets showed consistency for gene expression values (Table 4).

The comparison of non-columnar versus heterozygous columnar primary roots identified 194 significantly differentially expressed genes (see Additional file 3). Visualization in MapMan (Figure 2) showed that many genes were upregulated in heterozygous columnar roots when compared with non-columnar roots. This applied to genes involved in cellulose synthesis, cell wall modification and degradation, glycolysis, the oxidative pentose phosphate pathway, the biosynthesis of phenylpropanoids, starch and fatty acids and the mitochondrial electron transport. On the other hand, single genes involved in lipid and starch degradation and photorespiration were downregulated in the heterozygous columnar radicles (Figure 2A). Some genes associated with stress reactions such as ethylene biosynthesis and signaling (Figure 2B) were also more highly expressed in heterozygous columnar than in non-columnar primary roots. This also holds true for genes encoding the plastidic ribosomal proteins (Figure $2 \mathrm{C}$ ).

The comparison of non-columnar versus homozygous columnar primary roots yielded 269 significantly differentially expressed genes (see Additional file 4) and most of them were induced in homozygous columnar radicles (Figure 3). Single genes encoding components of the carbohydrate metabolism, cellulose synthesis, cell wall modification and degradation, the oxidative pentose phosphate pathway, fermentation, starch synthesis and ascorbate/

Table 2 Results of BLASTx searches against MDPs and Malus ESTs

\begin{tabular}{llllll}
\hline & \multicolumn{2}{l}{ MDPs } & & & \multicolumn{3}{l}{ Malus ESTs } \\
\cline { 2 - 3 } & $\begin{array}{l}\text { \# contigs with hits } \\
\text { (\% of total contigs) }\end{array}$ & $\begin{array}{l}\text { \# different hits } \\
\text { (\% of contigs with hits) }\end{array}$ & & $\begin{array}{l}\text { \# contigs with hits } \\
\text { (\% of total contigs) }\end{array}$ & $\begin{array}{l}\text { \# different hits } \\
\text { (\% of contigs with hits) }\end{array}$ \\
\hline PR (-/-) & $40010(83)$ & $25197(63)$ & $23966(64)$ & $38094(79)$ & $31484(83)$ \\
PR (Co/-) & $37666(85)$ & $25100(63)$ & $35816(81)$ & $30183(84)$ \\
PR (Co/Co) & $40110(82)$ & $19456(69)$ & $38208(78)$ & $31583(83)$ \\
PRs (-/-) & $28377(87)$ & $17481(69)$ & $26746(82)$ & $23621(88)$ \\
PRs (Co/-) & $25278(89)$ & $21350(67)$ & $23550(83)$ & $262(90)$ \\
PRs (Co/Co) & $32067(85)$ & $30071(80)$ & $26012(87)$ \\
\hline
\end{tabular}

The number and percentage of contigs yielding a hit and the number of different hits are indicated. The percentage of different hits refers to the total number of contigs and thus represents an estimate for the percentage of contigs representing individual genes. 
Table 3 Results of BLASTx searches against Malus Unigene and SwissPro/UniProtKB

\begin{tabular}{llllll}
\hline & \multicolumn{2}{l}{ Malus Unigene } & & \multicolumn{2}{l}{ SwissProt/UniProt KB } \\
\cline { 2 - 3 } & $\begin{array}{l}\text { \# contigs with hits } \\
\text { (\% of total contigs) }\end{array}$ & $\begin{array}{l}\text { \# different hits } \\
\text { (\% of contigs with hits) }\end{array}$ & & $\begin{array}{l}\text { \# contigs with hits } \\
\text { (\% of total contigs) }\end{array}$ & $\begin{array}{l}\text { \# different hits } \\
\text { (\% of contigs with hits) }\end{array}$ \\
\hline PR (-/-) & $31593(66)$ & $17379(55)$ & $16883(57)$ & $26221(55)$ & $11467(44)$ \\
PR (Co/-) & $29806(67)$ & $17288(55)$ & $24992(57)$ & $11238(45)$ \\
PR (Co/Co) & $31636(65)$ & $14437(64)$ & $26044(53)$ & $11404(44)$ \\
PRs (-/-) & $22545(69)$ & $13398(67)$ & $19102(59)$ & $9821(51)$ \\
PRs (Co/-) & $19923(70)$ & $15373(61)$ & $17111(60)$ & $9253(54)$ \\
PRs (Co/Co) & $25278(67)$ & $21343(57)$ & $10331(48)$ \\
\hline
\end{tabular}

The number and percentage of contigs yielding a hit and the number of different hits are indicated. The percentage of different hits refers to the total number of contigs and thus represents an estimate for the percentage of contigs representing individual genes.

glutathione metabolism were more highly expressed in the homozygous columnar radicles than in the non-columnar radicles (Figure 3A). On the other hand, single genes involved in fatty acid synthesis and lipid degradation, glycolysis, the tricarboxylic acid cycle, the mitochondrial electron transport chain and the Calvin cycle showed lower expression in the homozygous columnar roots than in the non-columnar primary roots. With regard to genes involved in stress reactions (Figure 3B), abscisic acid, ethylene and jasmonate-associated genes, genes encoding Myb transcription factors and peroxidases as well as genes involved in the maintenance of the redox state were upregulated. Genes linked to transcription and translation were also upregulated, and this holds true for nuclear as well as plastidic genes (Figure 3C).

When heterozygous and homozygous primary root samples were compared with each other, a similar picture emerged as for the analysis of non-columnar versus homozygous columnar radicles (see Additional file 5). 264 genes showed significant differential regulation (see Additional file 6) and of these, most genes were upregulated in the homozygous columnar primary roots. These genes are linked to primary and secondary metabolism (see Additional file 5A), stress reactions (see Additional file 5B) as well as transcription and translation (see Additional file $5 \mathrm{C}$ ). The only exceptions were some genes involved in glycolysis and mitochondrial electron transport, which showed a lower expression in homozygous columnar radicles than in heterozygous columnar radicles.
The differentially expressed genes identified in each of the three binary analyses were compared among each other (Figure 4). No genes were identified as differentially expressed in all three comparisons. 80 of the genes showing differences in gene expression between heterozygous and non-columnar radicles also show differential expression in homozygous columnar compared with noncolumnar radicles. 30 of the genes identified as differentially expressed in the heterozygous columnar versus the noncolumnar radicles were also differentially expressed in the heterozygous versus the homozygous columnar radicles. Another 39 genes differentially expressed in the heterozygous versus the homozygous columnar radicles were also differentially expressed in the homozygous columnar versus non-columnar radicles.

\section{Genes downstream of Gypsy-44 are downregulated in} radicles but upregulated in aerial organs of columnar plants In order to identify the link between the columnar-specific Gypsy-44 insertion and the columnar growth habit (most likely corresponding to the first, causal level of differential gene expression) we performed detailed expression analyses of all genes in the vicinity of the Gypsy-44 insertion. Eight genes that had previously been found to be transcribed and were annotated on our BAC metacontig based on the transcriptomic data [10] as well as Gypsy-44 itself were used for in-depth RNA-Seq and qRT-PCR analyses (Table 5, Figure 5). Fold changes were calculated for the primary root datasets as well as for three RNA-Seq Illumina datasets

Table 4 Pearson correlation coefficients of RNA-Seq libraries

\begin{tabular}{lllllll}
\hline & PR (-/-) & PRs (-/-) & PR (Co/-) & PRs (Co/-) & PR (Co/Co) & PRs (Co/Co) \\
\hline PR (-/-) & 1.00 & 0.84 & 0.80 & 0.83 & 0.85 & 0.86 \\
PRs (-/-) & & 1.00 & 0.91 & 0.98 & 0.95 & 0.96 \\
PR (Co/-) & & 1.00 & 0.93 & 0.93 & 0.89 \\
PRs (Co/-) & & & 1.00 & 0.95 & 0.96 \\
PR (Co/Co) & & & & 1.00 & 0.92 \\
PRs (Co/Co) & & & & & 1.00 \\
\hline
\end{tabular}

Correlation coefficients were calculated based on total read counts obtained for individual MDPs. 


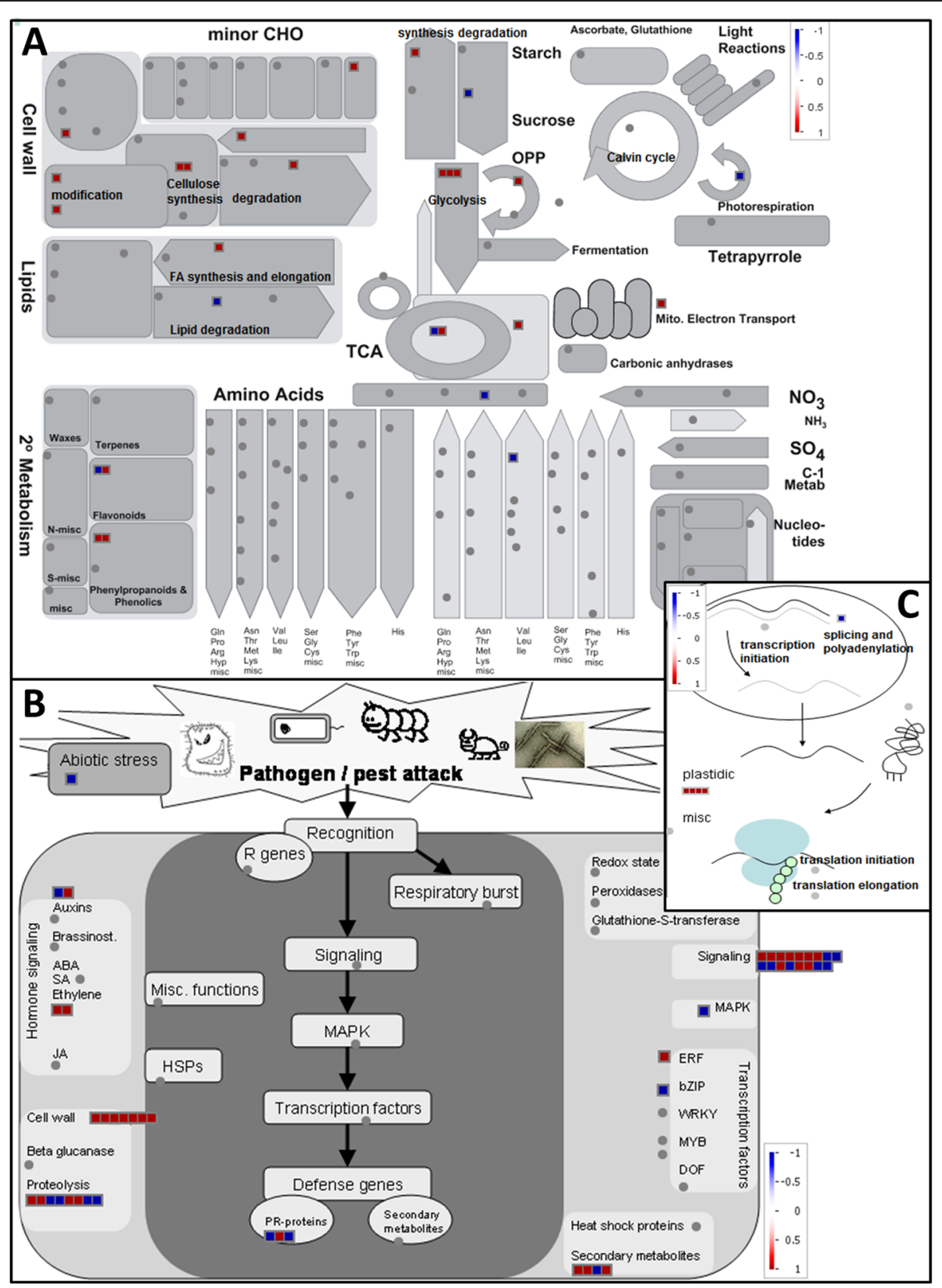

Figure 2 Differential gene expression in heterozygous compared with non-columnar primary roots. LOG2 fold changes of significantly differentially expressed genes (normalized to the non-columnar sample) as listed in Additional file 3 were imported and visualized in MapMan for the heterozygous columnar sample with regard to a metabolism overview (A), pathogen/pest attack (B) and transcription and translation (C). Genes upregulated in heterozygous columnar radicles are shown as red boxes, downregulated genes are shown as blue boxes.

each, generated from shoot apical meristems of A14 and P28 ([13,14], [EMBL: PRJEB2506]) and two transcriptomic datasets each, obtained from the total RNA of a McIntosh and a Wijcik leaf ([10], [EMBL: PRJEB1902]). If all genotypes of one tissue displayed read counts of 0 or 1 for a specific gene, this gene was considered not to be expressed (numeric read counts and fold changes can be found in Additional file 7). The results are shown in the upper part of Figure 5. At1g08530-like and MDP0000934866
(At1g06150-like) showed similar expression levels for columnar and non-columnar varieties in all samples analyzed. For MDP0000927091 (Autophagy9-like) and 5NG4like, similar levels of transcription were reached in all but the SAM3 dataset, in which they were induced in the columnar sample when compared with the non-columnar sample. Fold changes were less consistent between different tissues and across biological replicates for MDP0000912172 (PP2C15-like), MDP0000163720 (ACC1-like) and Gypsy-44 


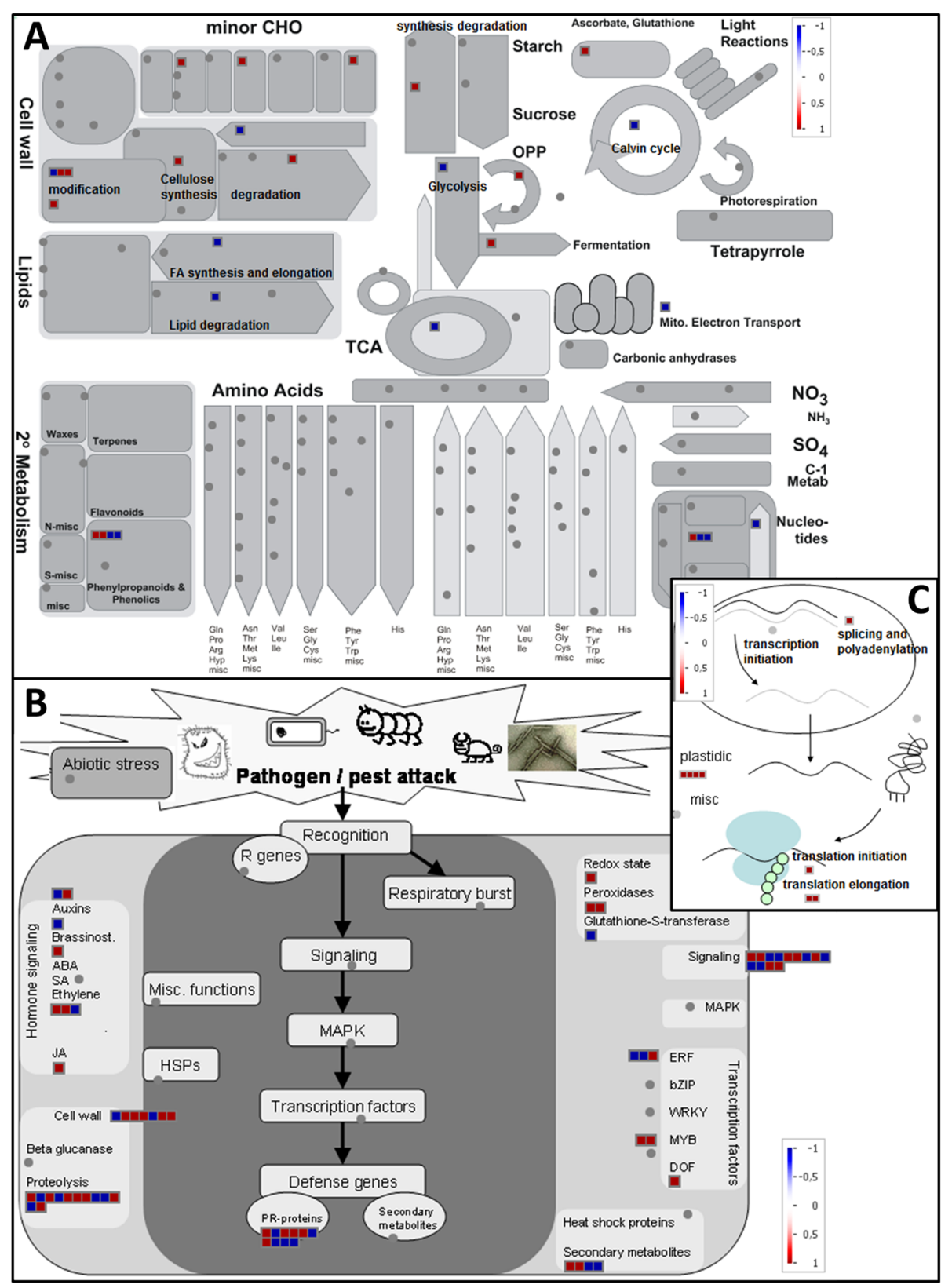

Figure 3 Differential gene expression in homozygous compared with non-columnar primary roots. LOG2 fold changes of significantly differentially expressed genes (normalized to the non-columnar sample) for the homozygous columnar sample as listed in Additional file 4 were imported and visualized in MapMan with regard to a metabolism overview (A), pathogen/pest attack (B) and transcription and translation (C). Genes upregulated in homozygous columnar radicles are shown as red boxes, downregulated genes are shown as blue boxes.

itself. For the former two genes, this might be caused by the generally lower expression level making fold changes prone to fluctuation. The most striking results were obtained for dmr6-like and MDP0000927098 (ATL5K-like), the first two protein coding genes that follow downstream of the Gypsy-44 insertion: they were downregulated in the primary root samples and strongly upregulated in the shoot apical meristem of columnar varieties. These effects were most pronounced for dmr6-like in the shoot apical meristem, where no or only basal transcription (0 reads or $1 \mathrm{read}$ ) occurred in non-columnar A14, while expression was 30-, 53- and 56-times higher in the three biological replicates of P28.

Gypsy-44 itself, its direct neighboring genes and all other genes within the $\mathrm{Co}$ target region showing interesting differential gene expression were subjected to qRT-PCRs in order to verify the RNA-Seq results (Figure 5, lower part). Overall, the qRT-PCR results were mostly consistent with 


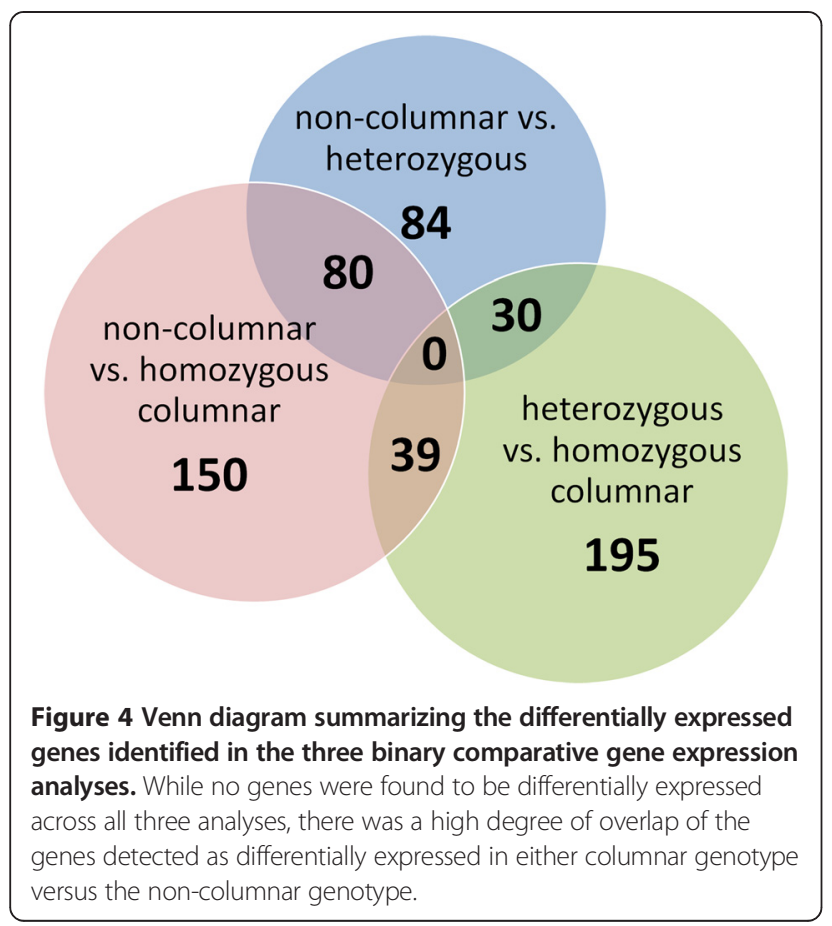

the RNA-Seq results. However, fold changes showed less variation across biological replicates in the qRT-PCRs than in the RNA-Seq data. Fold changes of around 1 were obtained for At1g08530-like and MDP0000934866 (At1g06150-like) for all tissues with the exception of a 2.5fold induction of MDP0000934866 in one of the shoot apical meristem samples. Gypsy-44 was upregulated in the shoot apical meristem, but downregulated in leaves and heterozygous primary roots. MDP0000163720 (ACC1-like) was induced in shoot apical meristems of P28 and slightly induced in heterozygous and homozygous primary roots of one replicate dataset. With regard to the two genes downstream of Gypsy-44, downregulation of MDP0000927098 (ATL5K-like) in columnar primary roots was corroborated, whereas its upregulation in the shoot apical meristem was less pronounced in the qRT-PCR than in the RNA-Seq data. In the qRT-PCR results for dmr6-like, downregulation was only detected when heterozygous radicles were compared with non-columnar radicles, but not when homozygous columnar radicles were compared with non-columnar radicles. Strong upregulation was detected in the Wijcik leaf when compared with the McIntosh leaf. The very strong induction of dmr6-like in the shoot apical meristem samples was validated by a 41 -fold and 202 -fold induction in the columnar shoot apical meristem replicates.

In order to identify any conserved cis-regulatory sequences of dmr6-like whose effect might be impaired by the insertion of Gypsy-44, we conducted comparative sequence analyses among the Rosaceae species apple, pear (Pyrus communis), peach (Prunus persica), Chinese plum (Prunus mume) and strawberry (Fragaria vesca). In these species, the genes flanking the Gypsy-44 insertion are microcolinear (with an inverse orientation on linkage group 2 of Fragaria), enabling the analysis of conserved non-coding sequences (CNSs) in the intergenic region. Remarkably, the intergenic region between At1g08530-like and dmr6-like or their orthologs has a size of about $33 \mathrm{~kb}$ in Malus (without the additional $8.2 \mathrm{~kb}$ of Gypsy-44), $6.8 \mathrm{~kb}$ in Pyrus, $1.7 \mathrm{~kb}$ in Fragaria and $1.4 \mathrm{~kb}$ in Prunus, suggesting that it has served as a popular target of TE insertions in the Pyreae and especially in the Malus lineage. Within this region, one CNS of about 400 bp showing two peaks in the identity plot could be observed about $31 \mathrm{~kb}$ upstream of dmr6-like in Malus (Figure 6). The sequence of the second peak region yielded a hit against a class II TE of the Mariner group in a CENSOR BLAST search [40], whereas no information could be obtained from database searches for the first part, suggesting that it might contain sequences conserved owing to their importance for gene regulation.

In conclusion, there is evidence that Gypsy-44 influences the expression level of its direct downstream gene, dmr6-like, and most likely also some genes located further downstream, possibly via impairment of the function of a CNS.

Table 5 Genes annotated on the BAC metacontig

\begin{tabular}{llll}
\hline Gene Name & Position on BAC Metacontig (strand) & Position on Chr $\mathbf{1 0}$ of GD Genome & Probable Function \\
\hline At1g08530-like & $49164-52233(+)$ & $18743425-18746497$ & unknown \\
dmr6-like & $93949-96036(+)$ & $18814292-18815452$ & defense reaction \\
MDP0000927098 (ATL5K-like) & $103945-104770(+)$ & $18853768-18854596$ & ubiquitination \\
MDP0000927091 (Autophagy9-like) & $119780-126200(-)$ & $18832988-18836788$ & recycling of cell components \\
5NG4-like & $140776-142998(-)$ & $18862782-18864480$ & auxin-induced transporter \\
MDP0000912172 (PP2C15-like) & $145267-146261(+)$ & $18866768-18867762$ & serine/threonine phosphatase \\
MDP0000934866 (At1g06150-like) & $169780-175840(+)$ & $18884175-18886818$ & bHLH transcription factor \\
MDP0000163720 (ACC1-like) & $184078-185923(-)$ & $18905698-18907541$ & ethylene biosynthesis \\
\hline
\end{tabular}

Eight genes were found to be expressed in at least one of the tissues investigated and were annotated on the BAC metacontig. Their name, position on the BAC metacontig and on chromosome 10 of the Golden Delicious (GD) draft genome sequence [36] as well as the possible function (according to BLAST searches) are indicated. bHLH, basic helix-loop-helix. 


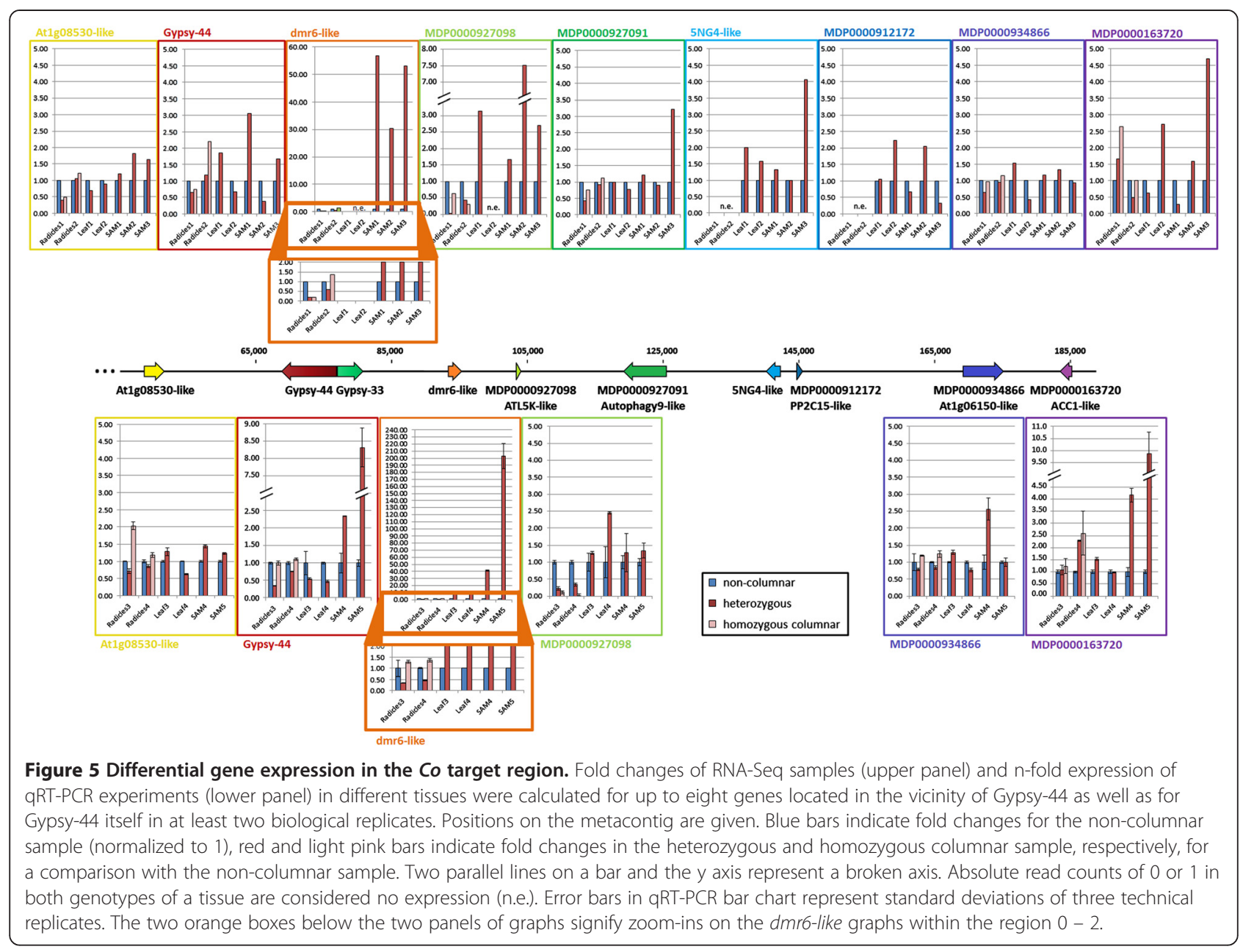

\section{Discussion}

\section{Genotyping, sequencing and assemblies}

So far, only heterozygous columnar cultivars have been described in the available literature, with one exception of a homozygous cultivar at Geisenheim University [10]. Therefore, Meulenbroek et al. [4] suggested that Co or a linked gene might negatively influence the fitness of pollen, seeds or early seedlings. However, crosses between two columnar apple trees have been shown to yield up to $75 \%$ columnar progeny $[4,41]$, which is in accordance with the result of dominant Mendelian inheritance comprising 25\% homozygous and 50\% heterozygous columnar plants. In our genotyping experiments with the progeny of a heterozygous columnar cultivar we detected $17 \%$ homozygous columnar radicles. Hence, homozygous columnar primary roots are clearly viable. They did not show any deviating phenotypic

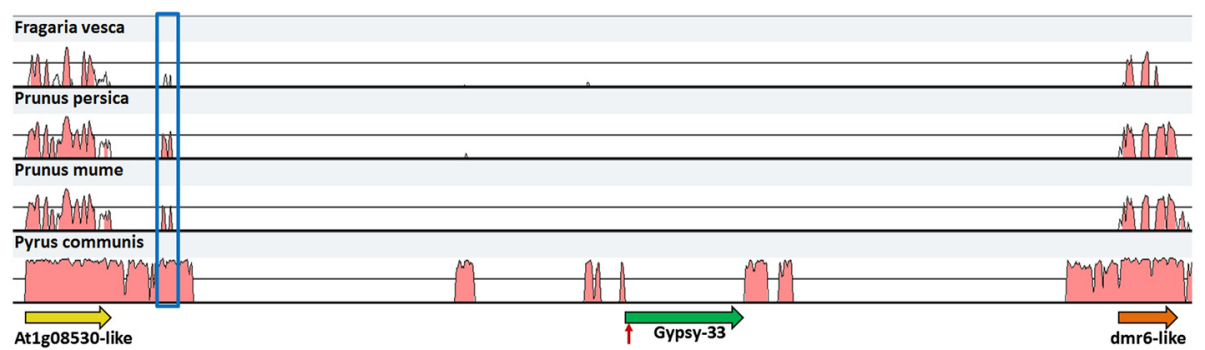

Figure 6 Conserved regions within the Gypsy-44 region. An mVISTA plot of sequence identity between the Malus $x$ domestica sequence spanning the region from At1g08530-like to dmr6-like ( $x$ axis) and different Rosaceae species indicates sequence conservation in exon regions and one CNS present in all species investigated (blue box). Other conserved regions in Pyrus correspond to TEs that probably inserted before the divergence of pear and apple. The red arrow marks the Gypsy-44 insertion site. 
differences either. The genotype ratio of non-columnar : heterozygous columnar : homozygous columnar of $2: 3: 1$ is not really surprising because seeds were obtained by open pollination.

In this study, we detected that apple primary roots express between 9,000 and 32,000 distinct genes (represented as contigs yielding different BLAST hits). The number of genes identified as expressed is dependent on the dataset and the criteria used to distinguish individual genes. Assembling the smaller replicate datasets produced less contigs than assembling the larger datasets because increased sequencing depth facilitates detection of a higher number of transcripts. Regarding the total number of active genes in primary roots, we consider the numbers obtained from BLAST searches against the Malus Unigene dataset, around 17,000, to be the best estimate for those genes that are assembled. MDP and EST most likely show redundancy, listing alleles or fragments of one gene as individual genes, and the SwissProt/UniProtKB probably does not contain all the apple-specific genes. However, considering that not all contigs matched to a Malus Unigene entry and that not all reads were assembled into contigs, the actual number of active genes is probably significantly higher than estimated. There is still a lot of discussion about the real number of genes in apple. Within its genomic sequence, almost 58,000 genes have been anchored, which is the highest gene number reported for plants so far, and this has even been considered an underestimate [36]. However, pear only has about 42,000 genes, and when the apple genome is re-assembled filtering out overlapping genes in apple chromosomes that might correspond to alleles instead of individual genes, the gene number drops down to 45,293 [42]. This would be more consistent with gene numbers of other close relatives such as peach $(27,852)[43]$ and strawberry $(34,809)$ [44]. Newcomb et al. [45] conducted one of the first exhaustive EST analyses in apple and found about 43,000 non-redundant sequences, which they considered to be approximately half of the apple genes. By contrast, Allan et al. [46] assumed the apple EST dataset of 68,599 sequences from databases to be an overestimate. On the other hand, based on EST analyses by Sanzol [47], 68\% of the apple genes fall into families with a mean copy number of 4.6 owing to several genome duplications, and the members of one family can have high sequence similarity but still represent different genes rather than alleles. Hence, the exact gene number remains debatable.

With regard to gene function, the well-known nonmodel-organism problem of an unsatisfying proportion of genes being successfully annotated is encountered [48]. We were able to assign GO terms to about $35 \%$ of contigs. This is slightly lower than the percentage of contigs annotated in RNA-seq studies of most other non-model organisms such as 50\% in ten different invertebrates [49], 47 and $48 \%$ in the non-model plants Streptocarpus rexii and olive, respectively [50,51], and $40 \%$ in the bloomforming alga Emiliania huxleyi [52]. However, it is much higher than the $15-19 \%$ of contigs contigs that could be successfully annotated in the non-model gastropod Nerita melanotragus [53]. Further efforts would most likely enable the assignment of possible functions to a higher number of contigs, similar to the techniques applied by [50]. Of those genes that were annotated, the majority had the expected function in growth, development and signaling, which is in agreement with the results obtained from transcriptome analyses of the poplar root and the Arabidopsis pericycle, where the most highly expressed genes were found to be involved in protein synthesis, metabolism, cellular communication and signal transduction $[20,22]$.

\section{Evaluation of differential gene expression}

DESeq was used to evaluate differential gene expression since it has been found to perform well in a comparison of DESeq, edgeR, baySeq and a method employing a two-stage Poisson model [54]. The comparison of gene expression in columnar and non-columnar radicles yields a lower number of significantly differentially expressed genes than the comparison of gene expression in columnar and non-columnar shoot apical meristems [13]. Differential expression was detected for $200-300$ and more than 600 genes in primary roots and shoot apical meristems, respectively, despite a more stringent definition of significant differential expression in the shoot apical meristem study of Krost et al. [13]. This might indicate that gene expression of columnar and non-columnar varieties is more similar in underground than in aerial organs. Alternatively, the difference in gene activity might be smaller in early developmental stages than at a higher age of the plants, which would explain the fact that the columnar growth habit can only be reliably detected after about $2-3$ years [55,56]. However, interpretation of the differential expression data is hampered by the fact that the genetic background of the individual radicles used for RNA extraction is unclear due to the open pollination of the flowers. While the mother plant is P28, the father could be any of the dozens of different varieties grown on the field. Additionally we have no knowledge about recombination that might have occurred within the gametes. We chose this material because we wanted to find out whether homozygous columnar individuals occur under natural field conditions. However, for gene expression analyses seeds obtained from targeted crossings would be much more favorable. Moreover, radicles consist of distinct developmental regions in the longitudinal direction and radicles were halved without detailed prior investigation so that different developmental zones most likely harboring different gene expression patterns might have been grouped to each RNA isolation sample. In future studies, the radicles should be subdivided into their individual zones by microscopic control (possibly after 
fluorescence in situ hybridization against marker genes of the distinct zones, similarly to [17]) and the gene expression should be investigated separately for each zone. Nevertheless, due to the high degree of correlation across samples with regard to active genes (see Additional file 2) and read counts for each gene (Table 4), we are confident that we analyzed samples of similar developmental zones and stages.

The pattern of differential gene expression in primary roots is in concordance with that of aerial plant parts. The differential expression of genes involved in cell wall biosynthesis and modification observed for heterozygous and homozygous columnar primary roots has already been described for shoot apical meristems of columnar trees [14]. In addition, an increased transcription of genes associated with jasmonate signaling and biosynthesis has been found for shoot apical meristems and leaves of columnar varieties $[10,13,14]$, and elevated ethylene signaling and biosynthesis seem to occur not only in columnar radicles, but also in leaves of columnar Wijcik compared with non-columnar McIntosh [10]. Therefore, alterations in cell boundary components and an increased level of jasmonates and ethylene might represent features of columnar apple trees that are already established in the early developmental stages and across different organs of the plantlet.

\section{The first level of differential gene expression occurs in the Gypsy-44 vicinity}

In a previous study [10] we found that columnar growth is most likely caused by the insertion of the Gypsy-44 LTR retrotransposon on chromosome 10 at $18.8 \mathrm{Mb}$, in accordance with the target region determined for the $\mathrm{Co}$ gene by Moriya et al. [57] and Baldi et al. [56]. Since it is a nested retrotransposon insertion, the link between its presence and the formation of the columnar phenotype remains to be unraveled. In this study, gene expression of Gypsy-44 itself and its neighboring genes was found to differ in columnar compared with non-columnar varieties in the individual plant organs. The expression of Gypsy-44 is induced in the shoot apical meristem. Its nearest downstream neighbor gene, dmr6-like, shows very strong (up to 200-fold) upregulation in shoot apical meristems and downregulation in the primary root samples of columnar individuals. The next gene downstream of dmr6-like, MDP0000927098 (ATL5K-like), and one other downstream gene, MDP0000163720 (ACC1-like), are also induced in shoot apical meristems of columnar P28. In contrast, expression of the upstream neighbor of Gypsy-44, At1g08530-like, remains unchanged. This indicates that Gypsy-44 influences the gene expression pattern of the downstream genes, especially dmr6-like, which has already been discussed as a possible candidate gene for the mediation of the columnar phenotype [10,12]. In addition to its induction in axillary meristems [12] and shoot apical meristems [10], dmr6-like is induced in our Wijcik leaf qRT-PCR samples, which were generated from RNA of the newly developing leaves near the top of the tree, but it shows no expression in the Wijcik leaf RNA-Seq data, which were obtained from RNA of young but fully developed leaves. We therefore conclude that dmr6-like is upregulated in all aerial organs of columnar trees that are important for the development of the plant organs showing differences between columnar and non-columnar plants: the shoot apical meristem, which is responsible for the formation of the short internodes and short lateral branches, the axillary meristem, which does not develop into lateral branches but instead produces short spurs, and the young leaves, which form a thicker palisade parenchyma with a high chlorophyll content [58]. In contrast, this upregulation does not occur in organs that have finished their development, such as older leaves, as well as in primary roots, which are less significant for the growth habit of the aerial organs; instead, a reverse regulation seems to take place on the below-ground organs. Wolters et al. [12] have already overexpressed dmr6-like in Arabidopsis and found the plants to have shorter internodes and smaller branches, strongly suggesting that dmr6-like is involved in the formation of the columnar growth habit. Our results support this hypothesis, but also raise further questions, e.g. how the tissue specificity of this induction is achieved.

Possible effects of the Gypsy-44 insertion like alterations in the methylation pattern or the allocation of enhancers and/or silencers have already been discussed [10]. The tissue specificity of this effect suggests that the Gypsy-44 insertion with a size of $8.2 \mathrm{~kb}$ might move a tissue-specific silencer of dmr6-like that is normally active in apical and axillary meristems and young developing leaves to a distance from the gene that abolishes silencer function, resulting in upregulation of dmr6-like. Alternatively, an enhancer being active in those tissues crucial for development might be moved into spatial proximity of dmr6-like due to an altered chromosome architecture (e.g. looping of the Gypsy-44 containing region) and thereby cause induction in tissues where dmr6-like is normally not expressed. We identified a candidate for a CNS that might have a role in gene regulation at $31.4 \mathrm{~kb}$ distance upstream of dmr6-like. This is reminiscent of the situation for the vgt1 locus in maize, a CNS positioned $70 \mathrm{~kb}$ downstream of ZmRap2.7. ZmRap2.7 is a repressor of flowering and its expression is downregulated in varieties that carry a miniature inverted repeat TE (MITE) insertion within $v g t 1$, resulting in early flowering [59]. However, in our case the TE insertion does not occur at the CNS site, but downstream of it. This might still influence its function due to the increased distance between the CNS and dmr6like. The fact that the region crucial for the formation of columnar growth, including dmr6-like, is conserved across several Rosaceae species might provide an opportunity for 
the creation not only of new columnar apple cultivars, but also of columnar pear and plum varieties by genetic engineering in future.

In Arabidopsis, dmr6 loss-of-function mutants show enhanced expression of a subset of defense-associated genes, suggesting a control different from that in apple [60]. Interestingly, the truncated protein of the dmr6-1 mutant is constitutively expressed in the shoot apical meristem and leaf primordia of Arabidopsis [60], in line with the expression profile of dmr6-like in columnar apple trees. The regulatory pathways influenced by columnar growth downstream of the dmr6-like upregulation still await elucidation. Since dmr6-like is associated with downy mildew resistance in Arabidopsis [60] it might trigger a defense response leading to a diseased-looking growth habit. On the other hand, members of the 2OG Fe(II) oxygenase family are involved in the biosynthesis of ethylene, gibberellins and flavonoids, the latter of which modulate polar auxin transport, so that upregulation of dmr6-like might directly influence phytohormone concentrations [12,61-64]. In apple, silencing of the chalcone synthase, the first committed enzyme in flavonoid biosynthesis, leads to decreased concentrations of flavonoids and causes altered cellular organization and cell wall composition, increased auxin transport and a reduction of plant size due to shortened internodes [65]. Specifically some genes encoding indole-3-acetic acid (IAA) transporters show upregulation in shoot apical meristem of P28 compared with A14, in line with an altered auxin transport capacity [13].

Furthermore, besides the induction of dmr6-like, other gene expression changes in the Gypsy-44 region or the upregulation of Gypsy-44 itself in shoot apical meristems might play a role in phenotype generation. Induction of MDP0000163720 in columnar shoot apical meristems, which encodes a homolog of Aminocyclopropane-1carboxylate oxidase, might lead to increased levels of ethylene. Since ethylene crosstalks with many other phytohormones such as auxin, cytokinin, abscisic acid, jasmonates and salicylic acid (for example [66-70]), this could contribute to the altered hormonal balance in columnar trees.

\section{Conclusions}

Open pollination of heterozygous columnar apple trees yield non-columnar, heterozygous columnar and homozygous columnar seedlings in a genotype ratio of $3: 2: 1$. This suggests that homozygous columnar plants are viable within their early life stages and the lack of described homozygous columnar varieties is probably due to breeders' selection criteria. Apple primary roots display a transcriptome profile typical for a developing and actively growing tissue. About 200 - 300 genes are differentially regulated in columnar compared with non-columnar radicles, and these are involved in cell wall synthesis and modification, stress reactions and phytohormone signaling and biosynthesis. The molecular cause of columnar growth, the Gypsy-44 insertion, leads to upregulation of its nearest downstream gene, dmr6-like, in all tissues that are crucial to the development of the visible plant growth habit. The role of dmr6-like in pathogen resistance possibly results in upregulation of defense reactions in aerial plant organs leading to a phenotype reminiscent of a diseased plant. Alternatively or additionally, the upregulation of dmr6-like might lead to alterations in flavonoid content causing altered auxin transport, which would be in line with changes in auxin signaling and metabolism that have been detected in previous studies. The Gypsy-44 insertion is the causative event, then leading to upregulation of dmr6like as a second step. In columnar primary roots, however, dmr6-like is downregulated, so that the activity of a tissuespecific transcriptional regulator might play a pivotal role. We are confident that our data will contribute to the elucidation of the whole signaling cascade causing columnar growth in apples.

\section{Methods}

\section{Plant material}

For primary root transcriptome studies, apples from the heterozygous columnar cultivar P28 obtained by open pollination on a field with many columnar apple trees were collected in August 2011 at Geisenheim University. Seeds were extracted and dried at room temperature for about $1-2$ weeks.

For qRT-PCRs, shoot tips of columnar P28 and noncolumnar 'A14-190-93K' (A14) sampled on September 29, 2009 and very young apical leaves of 'McIntosh' and 'McIntosh Wijcik' sampled on July 19, 2013 were snap frozen in dry ice or liquid nitrogen, respectively, and stored at $-80^{\circ} \mathrm{C}$ until further use.

\section{Seed germination}

Dried seeds were swabbed with $70 \%$ ethanol to roughly remove contamination and were placed in Petri dishes equipped with towel-paper that had been moistened with tap water. The petri dishes were wrapped in tinfoil and were stored in the dark at $4^{\circ} \mathrm{C}$ for about 12 weeks. When the radicles reached a length of about $2-3 \mathrm{~cm}$ they were snap frozen in liquid nitrogen, cut off the seed, cut in half and stored at $-80^{\circ} \mathrm{C}$ until further use.

\section{DNA isolation}

The upper half of each radicle was subjected to DNA extraction according to a manual protocol. One radicle was transferred into $500 \mu \mathrm{L}$ Cetyltrimethyl ammonium bromide (CTAB) extraction buffer, to which $168 \mu \mathrm{L} 8 \mathrm{M}$ urea and a spatula tip of polyvinylpyrrolidone (PVPP) were added. The radicle was thoroughly homogenized with a micropestle followed by incubation at $65^{\circ} \mathrm{C}$ for 
$30 \mathrm{~min}$. After centrifugation (10 min at 13,000 rpm and room temperature) the supernatant was purified by three chloroform isoamyl alcohol (24:1) extractions and subsequent ethanol precipitation.

\section{Primary root genotyping}

In order to investigate the genotype of each radicle with regard to the presence of the Gypsy-44 retrotransposon associated with the columnar growth habit, PCRs were performed with primers spanning the left border, the right border or the whole TE insertion as described by Otto et al. [10]. Results were double checked by PCRs with our indel-based markers I2_3_M1 and H1_M1 [37]. All primers were purchased from Invitrogen ${ }^{\mathrm{TM}}$ (Invitrogen, Darmstadt, Germany). PCRs were carried out in $50 \mu \mathrm{L}$ reaction volume containing at least $10 \mathrm{ng}$ of radicle DNA and $1 \mathrm{U}$ Go-Taq polymerase (Promega, Madison, United States) as follows: initial denaturation at $94^{\circ} \mathrm{C}$ for $5 \mathrm{~min}$ followed by 40 amplification cycles of denaturation at $94^{\circ} \mathrm{C}$ for $30 \mathrm{sec}$, annealing at $58.4^{\circ} \mathrm{C}$ or $60^{\circ} \mathrm{C}$ for $30 \mathrm{sec}$ and elongation at $72^{\circ} \mathrm{C}$ for 30 sec. A final elongation step at $72^{\circ} \mathrm{C}$ for $10 \mathrm{~min}$ was included. PCR products were analyzed on horizontal $2 \%$ agarose gels.

\section{RNA extraction}

The distal halves (tips) of radicles were used for RNA extraction. For the initial Illumina RNA-Seq, one radicle of each genotype was subjected to total RNA isolation. For replicate datasets, three frozen radicles of one genotype were pooled prior to RNA extraction. Total RNA was isolated using the innuPREP Plant RNA Kit (Analytik Jena, Jena, Germany) following the manufacturer's instructions. A DNase I (Fermentas, St. Leon-Roth, Germany) digestion step on the column was included to remove genomic DNA. RNA concentration and integrity were assessed with Bioanalyzer RNA Nano or Pico chips (Agilent, Santa Clara, USA).

For qRT-PCRs with leaf and shoot tip material, samples were transferred to liquid nitrogen, disrupted with a mortar and pestle and RNA was isolated using the innuPREP Plant RNA kit (Analytik Jena, Jena, Germany) following the manufacturer's instructions.

\section{Illumina sequencing}

For RNA-Seq library construction 500 ng of total RNA of each primary root sample were sent to GENterprise Genomics (Mainz, Germany). RNA Integrity Number (RIN) values were $7.6,7.8$ and 8.3 for the total RNA obtained from the single non-columnar, heterozygous columnar and homozygous columnar radicle, repectively. The RNA of the replicate samples had RIN values of 8.2, 7.0 and 7.0 for the non-columnar, the heterozygous columnar and the homozygous columnar genotype, respectively. $100 \mathrm{bp}$ paired-end runs were conducted on the Illumina
HiSeq 2000 or Illumina HiSeq 2500 (Illumina, San Diego, USA) of the IMSB Mainz.

\section{Assembly of Illumina data}

Prior to assembly, Illumina raw data were trimmed with an in-house Perl script to remove low quality stretches. $6 \mathrm{bp}$ at the 5 ' end and 5 bp at the 3' end were cut off, and bases with a Phred score $<20$ or called as "N" were removed. After trimming, only sequences with a minimum length of $30 \mathrm{bp}$ were maintained. All remaining sequences were assembled with the CLC Assembly Cell (CLC bio, Aarhus, Denmark) using different $\mathrm{k}$-mer sizes and a bubble size of 300. The assemblies yielding the highest N50 value were used for BLAST searches. To evaluate these assemblies, trimmed reads were mapped back to contigs with Bowtie [71], allowing no mismatches.

\section{BLAST searches}

Contigs generated by assembling were subjected to BLAST searches [33] against 1) MDPs representing the genes annotated in the Golden Delicious genome sequence [36] as extracted from the Genome Database of Rosaceae (http://www.rosaceae.org/), 2) the NCBI Malus expressed sequence tag (EST) dataset, 3) the Malus Unigene v5.0 dataset representing filtered ESTs assembled with CAP3 [72], available at the Genome Database of Rosaceae (http:// www.rosaceae.org/), and 4) the NCBI SwissProt/UniProtKB database, all databases downloaded on February 3, 2014. BLAST results were filtered and analyzed at an E-Value cutoff of $10^{-5}$.

\section{Blast2GO}

Results of BLAST searches with the replicate datasets against SwissProt/UniProtKB were imported into CLC Genomics Workbench v6.5 (CLC bio, Aaarhus, Denmark) and analyzed with the Blast2GO plugin using default parameters $[34,35]$. Following GO Slim reduction, combined graphs of the GO term biological process were created and were converted to pie charts of the second-level terms.

\section{RNA-Seq analysis}

Illumina raw sequencing data were imported into CLC Genomics Workbench v6.5 (CLC bio, Aaarhus, Denmark) as paired-end reads and were subjected to trimming and RNA-Seq mappings against our BAC metacontig of the transposon region or the Golden Delicious reference genome as previously described [10]. A similarity of at least $98 \%$ was demanded for at least $90 \%$ of the read length and using the "include broken pairs" counting scheme. For visualization of differential gene expression between two datasets each, total gene read counts for each MDP were extracted from RNA-Seq mapping results and analyzed in DESeq [38] with default parameters and 
including the biological replicates. Only genes with base mean $>100$, fold change $>2($ or $<0.5)$ and $p$-value $<0.05$ were maintained, and genes were ranked according to their p-values. Subsequently, the LOG2 fold changes were loaded into MapMan [39] and mapped against the Malus $\mathrm{x}$ domestica mapping file.

\section{qRT-PCRs}

Genes showing interesting differential regulation were subjected to qRT-PCR analysis in order to verify the bioinformatics results. Primers were designed to span the last intron of each gene and were purchased from Invitrogen (Darmstadt, Germany). A list of primers can be found in Additional file 8. $800 \mathrm{ng}$ of total RNA extracted from three pooled primary roots of each genotype (RIN $>7$ ) and $200 \mathrm{ng}$ of human MDA-MB468 RNA serving as exogenous control were converted to cDNA using SuperScript III Reverse Transcriptase (Invitrogen, Darmstadt, Germany) and $100 \mu \mathrm{M}$ oligo $(\mathrm{dT})_{18} \mathrm{VN}$ primer according to the manufacturer's instructions. In order to compare results of different tissues, the same procedure was applied to RNA extracted from shoot tips (shoot apical meristems) of A14 and P28 and to RNA isolated from young leaves of McIntosh and McIntosh Wijcik. All qRT-PCR experiments were carried out in a 7500 Fast Real-Time PCR System using Power SYBR Green PCR Master Mix (Applied Biosystems, Carlsbad, USA). Reactions were conducted in triplicate and two biological replicates were analyzed.

\section{Conserved sequence analysis}

Orthologs were retrieved from pear, peach, Chinese plum (Mei) and strawberry based on BLASTx searches yielding PCP006734.1 and PCP039177.1 (pear), ppa009607m and ppa014841m (peach), Pm020608 and Pm020609 (Chinese plum) and mrna08066.1-v1.0-hybrid and mrna08065.1v1.0-hybrid (strawberry) as the best hits for At1g08530like and dmr6-like, respectively. The corresponding genomic sequences were extracted from GDR and were aligned in mVISTA (http://genome.lbl.gov/vista/index. html) [73] with parameters "calculated window" of $100 \mathrm{bp}$, "minimum consensus width" $100 \mathrm{bp}$ and "consensus identity" $70 \%$.

\section{Availability of supporting data}

Transcriptomic Illumina data of primary roots, SAMs and leaves can be found in the EMBL EBI Short Read Archive under study accession numbers PRJEB6212 (http://www. ebi.ac.uk/ena/data/view/PRJEB6212), PRJEB2506 (http:// www.ebi.ac.uk/ena/data/view/PRJEB2506) and PRJEB1902 (http://www.ebi.ac.uk/ena/data/view/PRJEB1902), respectively. The annotated genomic contig of the Gypsy-44 region including all annotated genes can be retrieved from the EMBL EBI GenBank repository under accession number HF968765 (http://www.ebi.ac.uk/ena/data/view/
HF968765). All other supporting data can be found in the supplementary online material of this article.

\section{Additional files}

\begin{abstract}
Additional file 1: Pie charts of level $2 \mathrm{GO}$ terms assigned to contigs of primary root transcriptome assemblies. Assemblies of primary root transcriptome Illumina reads were subjected to BLAST searches against SwissProt/UniProtKB and subsequent Blast2GO analysis. Pie charts of level 2 GO terms are shown for data obtained from three pooled non-columnar (A), heterozygous columnar (B) and homozygous columnar (C) primary roots.
\end{abstract}

Additional file 2: Venn diagram of active genes in the datasets of the non-colmnar, heterozygous and homozygous columnar primary roots. Annotated MDPs to which at least one read of the original or replicate RNA-Seq dataset of primary roots could be mapped were considered active. Active genes were compared across genotypes. 46,417 genes are active in all three genotypes, 1385 genes are active in the non-columnar and the heterozygous columnar samples, but not in the homozygous colmnar samples. 1005 genes are expressed in the non-clumnar and the homozygous columnar roots, but not in the heterozygous columnar roots. 655 active genes are shared between heterozygous and homozygous columnar primary roots and are not expressed in non-columnar radicles. 630, 430 and 2845 genes are expressed only in the non-columnar, the hetrozygous and the homozygous columnar radicles, respectively.

Additional file 3: Table of significantly differentially expressed genes in heterozygous compared with non-columnar primary roots. Total gene reads of the two biological replicate data were imported into DESeq and analysed for differential expression. Only genes with base mean $>100$, fold change $>2$ and $p$-value $<0.05$ are displayed. The number of the MapMan BIN each gene was assigned to as well as the gene name, identifier (PAC-ID) and description are given as in the MapMan mapping file for apple.

Additional file 4: Table of significantly differentially expressed genes in homozygous columnar compared with non-columnar primary roots. Total gene reads of the two biological replicate data were imported into DESeq and analyzed for differential expression. Only genes with base mean $>100$, fold change $>2$ and $p$-value $<0.05$ are displayed. The number of the MapMan BIN each gene was assigned to as well as the gene name, identifier (PAC-ID) and description are given as in the MapMan mapping file for apple.

Additional file 5: Figure of differentially expressed genes in homozygous columnar compared with heterozygous primary roots. LOG2 fold changes of significantly differentially expressed genes (normalized to the heterozygous sample) as listed in Additional File 6 were imported and were visualized in MapMan for the homozygous columnar sample with regard to a metabolism overview (A), pathogen/pest attack (B) and transcription and translation (C). Genes upregulated in homozygous columnar radicles are shown as red boxes, downregulated genes are shown as blue boxes.

Additional file 6: Table of significantly differentially expressed genes in homozygous columnar compared with heterozygous primary roots. Total gene reads of the two biological replicate data were imported into DESeq and analyzed for differential expression. Only genes with base mean $>100$, fold change $>2$ and $p$-value $<0.05$ are displayed. The number of the MapMan BIN each gene was assigned to as well as the gene name, identifier (PAC-ID) and description are given as in the MapMan mapping file for apple.

Additional file 7: Table of total read counts and fold changes of genes and Gypsy-44 within the Co target region. Total Read counts of RNA-Seq data are displayed.

Additional file 8: Primer List. Primers used for marker PCRs and GRT-PCR.

\section{Abbreviations}

ACC1: 1-aminocyclopropane-1-carboxylate synthase 1; BLAST: Basic Local Alignment Search Tool; Co: Columnar; CNS: conserved non-coding sequence; CTAB: cetyltrimethyl ammonium bromide; dmr6: Downy mildew resistant 6; EST: Expressed sequence tag; GO: Gene Ontology; IAA: Indole-3 acetic acid; LTR: Long terminal repeat; MDP: Malus $x$ domestica protein; PP2C: Protein 
phosphatase 2C; PVPP: Polyvinylpyrrolidone; qRT-PCR: Quantitative real-time polymerase chain reaction.

\section{Competing interests}

The authors declare that they have no competing interests.

\section{Authors' contributions}

RP carried out differential gene expression analysis and qRT-PCRs and drafted the manuscript. HD participated in RNA-Seq analysis. BR conducted assemblies and BLAST searches. BR and SR analyzed assemblies and provided bioinformatics support. ERS initiated the project and supervised the project throughout. All authors read and approved the final manuscript.

\section{Acknowledgements}

We would like to thank the Institutes of Botany and Pomology of the Geisenheim University for providing Procats 28 apples, Clemens Krost for advice on DESeq and qRT-PCR analysis and Ramona Petersen for linguistic proofreading. We are grateful to Oliver Dautermann, Inessa Penner and Nina Seiwert for help with genotyping and RNA extraction. This work was supported by grants of the Federal Ministry of Agriculture and Nutrition (no. 511-06.01-28-1-43.042-07 and no. 313-06.01-28-1-43.042-07)

Received: 27 May 2014 Accepted: 27 November 2014 Published online: 04 February 2015

\section{References}

1. Lapins KO. Segregation of compact growth types in certain apple seedling progenies. Can J Plant Sci. 1969:49:765-8.

2. Tobutt KR. Breeding columnar apple trees at east malling. Acta Hortic. 1985;159:63-8

3. Gelvonauskienë D, Gelvonauskis B, Sasnauskas A. Impact of rootstock on columnar apple tree growth in a nursery. Sci Work Lith Inst Hortic Lith Univ Agric. 2006;25:51-6.

4. Meulenbroek J, Verhaegh J, Janse J. Inheritance studies with columnar type trees. Acta Hortic. 1998;484:255-8.

5. Moriya S, Iwanami H, Kotoda N, Takahashi S, Yamamoto T, Abe K. Development of a marker-assisted selection system for columnar growth habit in apple breeding. J Jpn Soc Hortic Sci. 2009;78:279-87.

6. Lauri PE, Lespinasse JM. The Relationship between cultivar fruiting-type and fruiting branch characteristics in apple trees. Acta Hortic. 1993;349:259-63.

7. Petersen $R$, Krost $C$. Tracing a key player in the regulation of plant architecture: the columnar growth habit of apple trees (Malus $\times$ domestica). Planta. 2013;238:1-22.

8. Fisher DV. Spur-type strains of mcintosh for high density plantings. Br Columbia Fruit Grow Assoc Q Rep. 1969;14:3-10.

9. Fisher DV. The "Wijcik Spur McIntosh.". Fruit Var J. 1995;49:212-3.

10. Otto D, Petersen R, Brauksiepe B, Braun P, Schmidt ER. The columnar mutation ("Co gene") of apple (Malus $\times$ domestica) is associated with an integration of a Gypsy-like retrotransposon. Mol Breed. 2014;33:863-80.

11. Tian Y-K, Wang C-H, Zhang J-S, James C, Dai H-Y. Mapping Co, a gene controlling the columnar phenotype of apple, with molecular markers. Euphytica. 2005;145:181-8.

12. Wolters PJ, Schouten HJ, Velasco R, Si-Ammour A, Baldi P. Evidence for regulation of columnar habit in apple by a putative 2OG-Fe(II) oxygenase. New Phytol. 2013;200:993-9.

13. Krost C, Petersen R, Lokan S, Brauksiepe B, Braun P, Schmidt ER. Evaluation of the hormonal state of columnar apple trees (Malus $\times$ domestica) based on high throughput gene expression studies. Plant Mol Biol. 2013;81:211-20.

14. Krost C, Petersen R, Schmidt ER. The Transcriptomes of Columnar and Standard Type Apple Trees (Malus $\times$ domestica) - a Comparative Study. Gene. 2012;498:223-30.

15. Darwin CR, assisted by DF. The Power of Movement in Plants. London: John Murray; 1880.

16. Baluska F, Mancuso S, Volkmann D, Barlow PW. The "root-brain" hypothesis of Charles and Francis Darwin: Revival after more than 125 years. Plant Signal Behav. 2009:4:1121-7.

17. Birnbaum K, Shasha DE, Wang JY, Jung JW, Lambert GM, Galbraith DW, et al. A gene expression map of the Arabidopsis root. Science. 2003;302:1956-60.

18. Nawy T, Lee J-Y, Colinas J, Wang JY, Thongrod SC, Malamy JE, et al. Transcriptional profile of the Arabidopsis root quiescent center. Plant Cell. 2005;17:1908-25.
19. Brady SM, Orlando DA, Lee J-Y, Wang JY, Koch J, Dinneny JR, et al. A highresolution root spatiotemporal map reveals dominant expression patterns. Science. 2007;318:801-6.

20. Dembinsky D, Woll K, Saleem M, Liu Y, Fu Y, Borsuk LA, et al. Transcriptomic and proteomic analyses of pericycle cells of the maize primary root. Plant Physiol. 2007;145:575-88.

21. Hoecker N, Lamkemeyer T, Sarholz B, Paschold A, Fladerer C, Madlung J, et al. Analysis of nonadditive protein accumulation in young primary roots of a maize (Zea mays L.) F1-hybrid compared to its parental inbred lines. Proteomics. 2008;8:3882-94.

22. Kohler A, Dalaruelle C, Martin D, Encelot N, Martin F. The poplar root transcriptome: analysis of 7000 expressed sequence tags. FEBS Lett. 2003;542:37-41.

23. Eichholtz DA, Robitaille HA, Herrmann KM. Protein Changes during the Stratification of Malus domestica Borkh. Seed Plant Physiol. 1983;72:750-3.

24. Bogatek R, Dziewanowska K, Lewak S. Hydrogen cyanide and embryonal dormancy in apple seeds. Physiol Plant. 1991;83:417-21.

25. Gniazdowska A, Dobrzyńska U, Babańczyk T, Bogatek R. Breaking the apple embryo dormancy by nitric oxide involves the stimulation of ethylene production. Planta. 2007;225:1051-7.

26. Gniazdowska A, Krasuska U, Debska K, Andryka P, Bogatek R. The beneficial effect of small toxic molecules on dormancy alleviation and germination of apple embryos is due to NO formation. Planta. 2010;232:999-1005.

27. Gniazdowska A, Krasuska U, Bogatek R. Dormancy removal in apple embryos by nitric oxide or cyanide involves modifications in ethylene biosynthetic pathway. Planta. 2010;232:1397-407.

28. Dębska K, Krasuska U, Budnicka K, Bogatek R, Gniazdowska A. Dormancy removal of apple seeds by cold stratification is associated with fluctuation in $\mathrm{H}_{2} \mathrm{O}_{2}$, NO production and protein carbonylation level. J Plant Physiol. 2013;170:480-8.

29. Petricka JJ, Winter CM, Benfey PN. Control of Arabidopsis root development. Annu Rev Plant Biol. 2012;63:563-90.

30. Dolan L, Janmaat K, Willemsen V, Linstead P, Poethig S, Roberts K, et al. Cellular organisation of the Arabidopsis thaliana root. Development. 1993;119:71-84.

31. Van den Berg C, Weisbeek P, Scheres B. Cell fate and cell differentiation status in the Arabidopsis root. Planta. 1998;205:483-91.

32. Van den Berg C, Willemsen V, Hendriks G, Weisbeek P, Scheres B. Short-range control of cell differentiation in the Arabidopsis root meristem. Nature. 1997;390:287-9.

33. Altschul SF, Gish W, Miller W, Myers EW, Lipman DJ. Basic local alignment search tool. J Mol Biol. 1990;215:403-10.

34. Conesa A, Götz S, García-Gómez JM, Terol J, Talón M, Robles M. Blast2GO: a universal tool for annotation, visualization and analysis in functional genomics research. Bioinformatics. 2005;21:3674-6.

35. Conesa A, Götz S. Blast2GO: a comprehensive suite for functional analysis in plant genomics. Int J Plant Genomics. 2008;2008:619832.

36. Velasco R, Zharkikh A, Affourtit J, Dhingra A, Cestaro A, Kalyanaraman A, et al. The genome of the domesticated apple (Malus $\times$ domestica Borkh). Nat Genet. 2010;42:833-9.

37. Otto D, Petersen R, Krost C, Schmidt ER, Brand R, Brauksiepe B, Braun P: Molecular Characterization of the Co Gene Region in Malus $\times$ domestica. Acta Hortic, under review.

38. Anders S, Huber W. Differential expression analysis for sequence count data. Genome Biol. 2010;11:R106.

39. Thimm O, Bläsing O, Gibon Y, Nagel A, Meyer S, Krüger P, et al. Mapman: a user-driven tool to display genomics data sets onto diagrams of metabolic pathways and other biological processes. Plant J. 2004;37:914-39.

40. Kohany O, Gentles AJ, Hankus L, Jurka J. Annotation, submission and screening of repetitive elements in Repbase: RepbaseSubmitter and Censor. BMC Bioinformatics. 2006;7:474.

41. Lapins KO. Inheritance of compact growth type in apple. J Am Soc Hortic Sci. 1976;101:133-5.

42. Wu J, Wang Z, Shi Z, Zhang S, Ming R, Zhu S, et al. The genome of the pear (Pyrus bretschneideri Rehd.). Genome Res. 2013;23:396-408.

43. Initiative TIPG. The high-quality draft genome of peach (Prunus persica) identifies unique patterns of genetic diversity, domestication and genome evolution. Nat Genet. 2013:45:487-94.

44. Shulaev V, Sargent DJ, Crowhurst RN, Mockler TC, Folkerts O, Delcher AL, et al. The genome of woodland strawberry (Fragaria vesca). Nat Genet. 2011;43:109-16. 
45. Newcomb RD, Crowhurst RN, Gleave AP, Rikkerink EHA, Allan AC, Beuning LL, et al. Analyses of expressed sequence tags from apple. Plant Physiol. 2006;141:147-66.

46. Allan AC, Crowhurst R, Gleave A, Newcomb R, Schaffer R. Apple Functional Genomics. In: Folta KM, Gardiner SE, editors. Genet Genomics Rosaceae. 2009. p. 121-42

47. Sanzol J. Dating and functional characterization of duplicated genes in the apple (Malus domestica Borkh.) by analyzing EST data. BMC Plant Biol. 2010;10:87.

48. Horan K, Jang C, Bailey-Serres J, Mittler R, Shelton C, Harper JF, et al. Annotating genes of known and unknown function by large-scale coexpression analysis. Plant Physiol. 2008;147:41-57.

49. Riesgo A, Andrade SCS, Sharma PP, Novo M, Pérez-Porro AR, Vahtera V, et al. Comparative description of ten transcriptomes of newly sequenced invertebrates and efficiency estimation of genomic sampling in non-moel taxa. Front Zool. 2012;9:33.

50. Chiara M, Horner DS, Spada A. De novo assembly of the transcriptome of the non-model plant streptocarpus rexii employing a novel heuristic to recover locus-specific transcript clusters. PLoS One. 2013;8:e80961.

51. Alagna F, D'Agostino N, Torchia L, Servili M, Rao R, Pietrella M, et al. Comparative 454 pyrosequencing of transcripts from two olive genotypes during fruit development. BMC Genomics. 2009;10:399.

52. Feldmesser E, Rosenwasser S, Vardi A, Ben-Dor S. Improving transcriptome construction in non-model organisms: integrating manual and automated gene definition in Emiliana huxleyi. BMC Genomics. 2014;15:148.

53. Amin S, Prentis PJ, Gilding EK, Pavasovic A. Assembly and annotation of a non-model gastropod (Nerita melanotragus) transcriptome: a comparison of De novo Assemblers. BMC Res Notes. 2014;7:488.

54. Kvam VM, Liu P, Si Y. A comparison of statistical methods for detecting differentially expressed genes from RNA-seq data. Am J Bot. 2012;99:248-56.

55. Blazek J. Segregation and general evaluation of spur type or compact growth habits in apples. Acta Hortic. 1992;317:71-9.

56. Baldi P, Wolters PJ, Komjanc M, Viola R, Velasco R, Salvi S. Genetic and physical characterisation of the locus controlling columnar habit in apple (Malus $\times$ domestica Borkh.). Mol Breed. 2012;31:429-40.

57. Moriya S, Okada K, Haji T, Yamamoto T, Abe K. Fine mapping of Co, a gene controlling columnar growth habit located on apple (Malus $\times$ domestica Borkh.) Linkage Group 10. Plant Breed. 2012;131:641-7.

58. Zhang Y, Dai HY. Comparison of photosynthetic and morphological characteristics, and micro-structure of roots and shoots, between columnar apple and standard apple trees of hybrid seedlings. Phyton. 2011;80:119-25.

59. Salvi S, Sponza G, Morgante M, Tomes D, Niu X, Fengler KA, et al. Conserved noncoding genomic sequences associated with a flowering-time quantitative trait locus in maize. Proc Natl Acad Sci U S A. 2007;104:11376-81.

60. Van Damme M, Huibers RP, Elberse J, Van den Ackerveken G. Arabidopsis DMR6 encodes a putative 2OG-Fe(II) oxygenase that is defense-associated but required for susceptibility to downy mildew. Plant J. 2008;54:785-93.

61. Prescott AG, John P. DIOXYGENASES: molecular structure and role in plant metabolism. Annu Rev Plant Physiol Plant Mol Biol. 1996;47:245-71.

62. Brown DE, Rashotte AM, Murphy AS, Normanly J, Tague BW, Peer WA, et al. Flavonoids act as negative regulators of auxin transport in vivo in Arabidopsis. Plant Physiol. 2001;126:524-35.

63. Peer WA, Murphy AS. Flavonoids and auxin transport: modulators or regulators? Trends Plant Sci. 2007;12:556-63.

64. Buer CS, Imin N, Djordjevic MA. Flavonoids: new roles for old molecules. J Integr Plant Biol. 2010;52:98-111.

65. Dare AP, Tomes S, Jones M, McGhie TK, Stevenson DE, Johnson RA, et al. Phenotypic changes associated with RNA interference silencing of chalcone synthase in apple (Malus X domestica). Plant J. 2013;74:398-410.

66. Chae HS, Cho YG, Park MY, Lee MC, Eun MY, Kang BG, et al. Hormonal cross-talk between auxin and ethylene differentially regulates the expression of two members of the 1-aminocyclopropane-1-carboxylate oxidase gene family in rice (Oryza sativa L.). Plant Cell Physiol. 2000;41:354-62.

67. Stepanova AN, Yun J, Likhacheva AV, Alonso JM. Multilevel interactions between ethylene and auxin in Arabidopsis roots. Plant Cell. 2007;19:2169-85.

68. El-Showk S, Ruonala R, Helariutta Y. Crossing paths: cytokinin signalling and crosstalk. Development. 2013;140:1373-83.

69. Leon-Reyes A, Spoel SH, De Lange ES, Abe H, Kobayashi M, Tsuda S, et al. Ethylene modulates the role of NONEXPRESSOR OF PATHOGENESISRELATED GENES1 in cross talk between salicylate and jasmonate signaling. Plant Physiol. 2009;149:1797-809.
70. Ghassemian M, Nambara E, Cutler S, Kawaide H, Kamiya Y, McCourt P. Regulation of abscisic acid signaling by the ethylene response pathway in Arabidopsis. Plant Cell. 2000;12:1117-26.

71. Langmead B, Trapnell C, Pop M, Salzberg SL. Ultrafast and memory-efficient alignment of short DNA sequences to the human genome. Genome Biol. 2009;10:R25.

72. Huang X, Madan A. CAP3: A DNA sequence assembly program. Genome Res. 1999:9:868-77.

73. Frazer KA, Pachter L, Poliakov A, Rubin EM, Dubchak I. VISTA: computational tools for comparative genomics. Nucleic Acids Res. 2004;32(Web Server issue): W273-9.

\section{Submit your next manuscript to BioMed Central and take full advantage of:}

- Convenient online submission

- Thorough peer review

- No space constraints or color figure charges

- Immediate publication on acceptance

- Inclusion in PubMed, CAS, Scopus and Google Scholar

- Research which is freely available for redistribution 